\title{
Electrospun Polyester/Cyclodextrin Nanofibers for Entrapment of Volatile Organic Compounds
}

\author{
Fatma Kayaci, ${ }^{1,2}$ Tamer Uyar ${ }^{1,2}$ \\ ${ }^{1}$ Institute of Materials Science \& Nanotechnology, Bilkent University, Ankara 06800, Turkey \\ 2 UNAM-National Nanotechnology Research Center, Bilkent University, Ankara 06800, Turkey
}

\begin{abstract}
Polyester (PET) nanofibers incorporating cyclodextrins (CD) were obtained via electrospinning. $\alpha-C D, \beta-C D$, and $\gamma-C D$ were used to functionalize PET nanofibers. Beadfree PET/CD nanofibers were obtained from lower polymer concentration indicating that the incorporation of CD in polymer solution improved the electrospinnability of the PET nanofibers. XRD studies indicated that CD were distributed into nanofiber without forming crystalline aggregates. FTIR peak shift was observed possibly due to interaction between CD and PET. TGA confirmed that initial CD loading $(25 \%, w / w)$ in the polymer solution was preserved for the PET/CD nanofibers. The presence of most of $C D$ on the surface of PET/CD nanofibers was confirmed by XPS analysis and contact angle measurement. DMA results indicated that incorporation of CD improved the mechanical property of the nanofibers. Our studies showed that PET/CD nanofibers can effectively entrap aniline vapor as a model volatile organic compound (VOC) from surrounding owing to their very large surface area and inclusion complexation capability of CD. The entrapment efficiency of aniline vapor was found to be better for PET/ $\gamma$-CD nanofibers compared to PET/ $\alpha-C D$ and $P E T / \beta-C D$ nanofibers. Our findings suggested that electrospun PET nanofibers functionalized with CD may be used as filtering material for removal of VOC in air filtration. POLYM. ENG. SCI., 54:2970-2978, 2014. (c) 2014 Society of Plastics Engineers
\end{abstract}

\section{INTRODUCTION}

The electrospun nanofibrous materials can be used as advanced filtering membranes for air and liquid filtrations [1, 2]. More efficient and energy saving innovative membrane materials are very demanding for removal of volatile organic compounds (VOCs), chemical and biological pollutants, warfare contaminants, and toxic agents from air, water, and surroundings [1-8]. Air filtration can be effectively achieved by using electrospun nanofibrous membranes due to their exclusive properties such as very high surface area to volume ratio, high permeability, low basis weight, and nanoporous structure [1-13]. Electrospinning is a cost-effective and quite versatile technique for nanofiber production [14-16], and a wide variety of nanofibrous

Correspondence to: Tamer Uyar; e-mail: tamer@unam.bilkent.edu.tr Contract grant sponsors: TUBITAK-The Scientific and Technological Research Council of Turkey (project \#110M612), EU FP7-PEOPLE-2009RG Marie Curie-IRG (NANOWEB, PIRG06-GA-2009-256428), The Turkish Academy of Sciences-Outstanding Young Scientists Award Program (TUBA-GEBIP) (to T.U.); contract grant sponsors: TUBITAK-BIDEB (national Ph.D. study scholarship to F.K.).

DOI 10.1002/pen.23858

Published online in Wiley Online Library (wileyonlinelibrary.com).

(C) 2014 Society of Plastics Engineers filtration membranes made of polymeric or inorganic nanofibers or polymer/nanoparticle composite nanofibers can be simply produced by using this technique [6, 7, 14-21].

The electrospun nanofibrous membranes functionalized with active agents such as cyclodextrins (CD) can provide efficient separation or purification performances [5, 22-29]. $\mathrm{CD}$ are derived from starch, and they are natural and nontoxic cyclic oligosaccharides having a truncated cone shaped molecular structure [30]. CD are quite applicable in pharmacy, cosmetics, food, and textiles due to their capability to form inclusion complexes with variety of molecules through noncovalent host-guest interactions [30-32]. CD have also shown potentials as a filtering material due to their capacity to remove organic waste molecules by inclusion complexation $[33,34]$. The production of electrospun nanofibers incorporating $\mathrm{CD}$ is our particular interest, since $\mathrm{CD}$-functionalized nanofibers can entrap organic waste compounds from the surroundings [22-28]. Recently, several studies were reported for the removal of organic molecules from liquid media [22, 23, 25-29] and vapor phase [24] by electrospun nanofibers incorporating CD. However, CD are water soluble, so physically bounded $\mathrm{CD}$ onto nanofibers could leach out from the nanofiber matrix during the filtration in aqueous medium. Yet, removal of VOCs by CD-functionalized nanofibers is possible without any leaching problem [24] since the nanofibrous membranes are not subjected to water, so these nanofibers can be promising filtering material for air filtration.

In this study, we have produced the CD-functionalized polyester (PET/CD) nanofibers by means of electrospinning (Fig. 1a). PET is a suitable polymer type for filtration application, and surface-associated CD molecules onto PET nanofibers can entrap VOCs from the surroundings for air filtration purpose. Three types of native $\mathrm{CD} ; \alpha-\mathrm{CD}, \beta-\mathrm{CD}$, and $\gamma-\mathrm{CD}$ having six, seven, and eight glucopyranose units, respectively, were used for a comparative study. These CD have the same cavity depth which is approximately $7.8 \AA$, whereas the cavity diameter for $\alpha-\mathrm{CD}, \beta-\mathrm{CD}$, and $\gamma-\mathrm{CD}$ are approximately 6,8 , and $10 \AA$, respectively (Fig. 1b) [30]. Since inclusion complexation formation depends on the size match and binding forces between CD cavity and guest molecule [35], each CD type can have different capability for the inclusion complexation with the same guest molecule. In this study, the morphological, structural, thermal, and surface characteristics of PET/CD nanofibers were examined. Moreover, the entrapment capability of the PET/CD nanofibrous webs was investigated by removal of a model VOC (aniline vapor) from the surrounding. The entrapment efficiency of PET/CD nanofibers (PET/ $\alpha-\mathrm{CD}, \mathrm{PET} / \beta-\mathrm{CD}$, $\mathrm{PET} / \gamma-\mathrm{CD})$ for aniline vapor was different from each other, yet, all three types of PET/CD nanofibers performed better entrapment of aniline when compared to that of PET nanofibers without CD. 

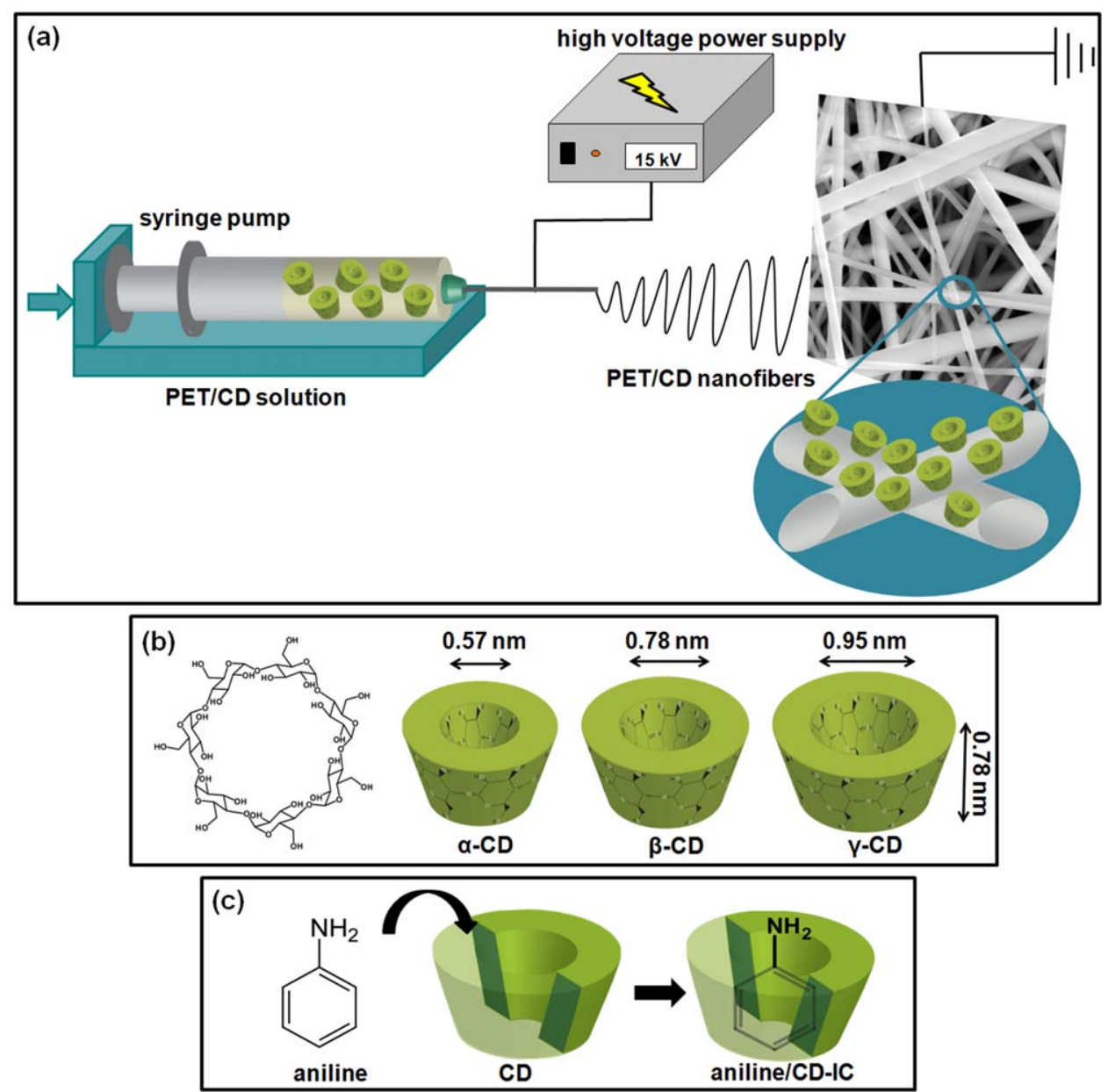

FIG. 1. Schematic representations of (a) electrospinning of PET/CD solution, (b) chemical structure of $\beta$-CD and approximate dimensions of $\alpha-\mathrm{CD}, \beta-\mathrm{CD}, \gamma-\mathrm{CD}$, and (c) formation of aniline/CD-IC. [Color figure can be viewed in the online issue, which is available at wileyonlinelibrary.com.]

\section{MATERIALS AND METHODS}

\section{Materials}

Three types of native $\mathrm{CD} ; \alpha-\mathrm{CD}, \beta-\mathrm{CD}$ and $\gamma$-CD were purchased from Wacker Chemie AG. Polyester (polyethylene terephthalate, PET) chips were gift from the company of Korteks (Bursa, Turkey). Dichloromethane (DCM, Sigma Aldrich, extra pure), trifluoroacetic acid (TFA, Sigma Aldrich, 99\%), acetonitrile chromasolv (Sigma Aldrich, 99.9\%), and aniline (Sigma
Aldrich, 99\%) were purchased. All materials were used asreceived without any further purification.

\section{Preparation of the Solutions for Electrospinning}

PET/CD solutions were prepared by dissolving PET and CD $(\alpha-\mathrm{CD}, \beta-\mathrm{CD}$, and $\gamma-\mathrm{CD})$ in TFA/DCM $(1 / 1, \mathrm{v} / \mathrm{v})$ solvent system. The polymer concentration was $20 \%(\mathrm{w} / \mathrm{v}$, with respect to the solvent), and the $\mathrm{CD}$ concentration was $25 \%$ (w/w, with

TABLE 1. Properties of PET and PET/CD solutions and the resulting electrospun nanofibers.

\begin{tabular}{|c|c|c|c|c|c|c|c|}
\hline Samples & $\begin{array}{l}\% \text { PET } \\
(\mathrm{w} / \mathrm{v})^{\mathrm{a}}\end{array}$ & $\begin{array}{l}\text { CD type } \% \\
(\mathrm{w} / \mathrm{w})^{\mathrm{b}}\end{array}$ & Viscosity (cP) & $\begin{array}{c}\text { Conductivity } \\
(\mu \mathrm{s} / \mathrm{cm})\end{array}$ & AFD (nm) & $\begin{array}{l}\text { Fiber diameter } \\
\text { range }(\mathrm{nm})\end{array}$ & Fiber morphology \\
\hline PET & 20 & - & 112.8 & 0.87 & $360 \pm 100$ & $150-660$ & Beaded nanofibers \\
\hline PET & 22.5 & - & 139.8 & 0.76 & $820 \pm 150$ & $620-1040$ & Bead-free nanofibers \\
\hline $\mathrm{PET} / \alpha-\mathrm{CD}$ & 20 & $\alpha-C D, 25 \%$ & 170.9 & 1.84 & $900 \pm 560$ & $160-2330$ & Bead-free nanofibers \\
\hline $\mathrm{PET} / \beta-\mathrm{CD}$ & 20 & $\beta-\mathrm{CD}, 25 \%$ & 134.6 & 1.90 & $830 \pm 510$ & $300-2200$ & Bead-free nanofibers \\
\hline $\mathrm{PET} / \gamma-\mathrm{CD}$ & 20 & $\gamma-\mathrm{CD}, 25 \%$ & 123.9 & 1.69 & $790 \pm 490$ & $310-2740$ & Bead-free nanofibers \\
\hline
\end{tabular}

${ }^{a}$ With respect to solvent (TFA/DCM, v/v, 1/1).

${ }^{b}$ With respect to polymer (PET). 
respect to the polymer) in these solutions. Moreover, 20\% and $22.5 \%$ (w/v, with respect to the solvent) PET solutions without $\mathrm{CD}$ were also prepared. Table 1 summarizes the compositions of all solutions used for electrospinning.

\section{Electrospinning}

The PET and PET/CD solutions were loaded into $5 \mathrm{~mL}$ syringes fitted with a metallic needles $(0.7 \mathrm{~mm}$ outer diameter), individually. The syringes were placed horizontally on the syringe pump (KDS 101, KD Scientific). A grounded stationary cylindrical metal collector (height: $15 \mathrm{~cm}$, diameter: $9 \mathrm{~cm}$ ) covered by a piece of aluminum foil was used for the fiber deposition. The feed rates of the solutions were $1 \mathrm{~mL} / \mathrm{h}$ during electrospinning, and needle tips-to-collector distances were set to $10 \mathrm{~cm}$. The high voltage power supply (Matsusada, AU Series) was used to apply a voltage of $15 \mathrm{kV}$. The electrospinning processes were performed at $22^{\circ} \mathrm{C}$ and $46 \%$ relative humidity in an enclosed Plexiglas box.

\section{Measurements and Characterizations}

The viscosity measurement of the each solution used for electrospinning was performed by using the Brookfield DVII+Pro viscometer equipped with cone/plate accessory of spindle type $\mathrm{CP} 42$ with $20 \mathrm{rpm}$ at $22^{\circ} \mathrm{C}$. The conductivity of the solutions was measured by using Mettler Toledo conductivity meter (LE705, Five Easy FE 30) at $24^{\circ} \mathrm{C}$. Scanning electron microscope (SEM, FEI-Quanta 200 FEG) was used to investigate the morphology of PET and PET/CD nanofibers. The samples were coated with $5 \mathrm{~nm} \mathrm{Au} / \mathrm{Pd}$ prior to SEM analysis. Around 100 fiber diameters of each sample were measured from the SEM images to determine the average fiber diameter (AFD) of the samples. X-ray diffraction (XRD) data of the nanofibers were collected by using PANalytical X'Pert Powder diffractometer with $\mathrm{Cu} K \alpha$ radiation in a range $2 \theta=5^{\circ}-30^{\circ}$. The infrared spectra of the electrospun nanofibers were recorded from 600 to $2000 \mathrm{~cm}^{-1}$ with a resolution of $4 \mathrm{~cm}^{-1}$ and 64 scans by using fourier transform infrared (FTIR) spectroscopy (Bruker-VERTEX 70). A small amount of each sample was mixed with potassium bromide ( $\mathrm{KBr}$, FTIR grade) in a mortar and then pellet was obtained by applying high pressure for FTIR analyses. The thermal properties of the samples were investigated by using thermogravimetric analyzer (TGA, TA Q500). In TGA measurements, the nanofibers were heated from room temperature to $600^{\circ} \mathrm{C}$ at a constant heating rate of $20^{\circ} \mathrm{C} / \mathrm{min}$ under the nitrogen atmosphere. The surface chemical characterization of the PET and PET/CD nanofibers were performed by X-ray photoelectron spectroscopy (XPS, Thermo Scientific). XPS data were taken by a flood gun charge neutralizer system equipped with a monochromated Al K- $\alpha$ X-ray source $(h v=1486.6 \mathrm{eV})$ from $400 \mu \mathrm{m}$ spot size on the nanofibers. Wide energy survey scans of the nanofibers were recorded over the $0-1360 \mathrm{eV}$ binding energy range, at detector pass energy of $200 \mathrm{eV}$, and with energy step size of $1 \mathrm{eV}$. The $\mathrm{O} 1 \mathrm{~s}$ high resolution spectra of the nanofibers were also obtained at pass energy of $50 \mathrm{eV}$ and with energy steps of $0.1 \mathrm{eV}$. The static water contact angles on the nanofibrous webs were evaluated using contact angle analyzing instrument (OCA30, Dataphysics Instrument Company) at room temperature. Deionized water $(0.4 \mu \mathrm{L})$ was automatically dropped on the webs and Laplace-Young fitting was applied on contact angle measurements. The measurement was repeated 10 times at different places of the PET nanofibrous web to get average contact angle value. The stress-strain curves for the nanofibrous webs were obtained using a dynamic mechanical analyzer (DMA, TA Q800) in tension film clamp at a constant stress rate of $2 \mathrm{~N} / \mathrm{min}$. The samples having size of $10 \mathrm{~mm}$ (gap) $\times 2.75 \mathrm{~mm}$ (width) $\times 0.35 \mathrm{~mm}$ (thickness) was measured. Ultimate stress and elongation at break of electrospun nanofibers were determined from the obtained stress-strain curves, and young modulus was calculated from the linear region of these curves. The average and standard deviation of these values were calculated by testing three specimens for each sample.

\section{Entrapment of Organic Vapor Waste by the Nanofibrous Webs}

The molecular entrapment capability of PET, PET/ $\alpha-\mathrm{CD}$, $\mathrm{PET} / \beta-\mathrm{CD}$, and PET $/ \gamma-\mathrm{CD}$ nanofibrous webs was tested by evaluating the amount of entrapped aniline (a model VOC) in vapor phase. This experiment was carried out in a sealed glass desiccator $(30 \mathrm{~cm}$ (diameter) and $30 \mathrm{~cm}$ (height)). First, $10 \mathrm{~mL}$ of aniline (as-received, without any dilution) was put into glass Petri dish, and it was placed at the bottom of desiccator. Then, three pieces of PET, PET/ $\alpha-\mathrm{CD}, \mathrm{PET} / \beta-\mathrm{CD}$, and $\mathrm{PET} / \gamma-\mathrm{CD}$ rectangular shaped nanofibrous webs $(50 \mathrm{mg}$, about $3 \mathrm{~cm} \times 4 \mathrm{~cm})$ were placed on the supporting layer which positioned at $7 \mathrm{~cm}$ high from the bottom of desiccator. The webs were left in this sealed desiccator for $12 \mathrm{~h}$ and exposed to aniline vapor. Afterward, the webs were removed from desiccator and kept in the suction hood for $3 \mathrm{~h}$ to remove the excess aniline molecules that were absorbed by the electrospun webs. To investigate the amount of aniline entrapped by the webs, high performance liquid chromatography (HPLC, Agilent 1200 series) equipped with VWD UV detector was used. First, each of the web was immersed in $2 \mathrm{~mL}$ acetonitrile (ACN), individually, and kept in it for $3 \mathrm{~h}$ to extract aniline entrapped by the nanofibers. $0.5 \mathrm{~mL}$ of each solution was withdrawn and put into HPLC vial to measure aniline concentration in these solutions. Aniline was detected by using the Agilent C18 column $(150 \mathrm{~mm} \times 4.6 \mathrm{~mm}$, $5 \mu \mathrm{m}$ pores) at $254 \mathrm{~nm}$. ACN (100\%) was used as a mobile phase. Flow rate, injection volume, and total run time were 0.5 $\mathrm{mL} / \mathrm{min}, 5 \mu \mathrm{L}$, and $4 \mathrm{~min}$, respectively. After the calibration curve $\left(R^{2}=0.996\right)$ was prepared by using aniline solutions having different concentrations (500 ppm, 1000 ppm, 2000 ppm, $4000 \mathrm{ppm}$ ), the filtrated aniline amount was determined by converting the aniline peak area to concentration (ppm) from the curves in HPLC chromatograms. The results were reported as the average \pm standard deviation of aniline concentration entrapped by the nanofibrous webs since three different samples were used for each web.

\section{RESULTS AND DISCUSSION}

\section{Morphological Characterization of the Nanofibers}

The characteristics (composition, viscosity, and conductivity) of the PET and PET/CD solutions, AFD, fiber diameter ranges and morphological characteristics of the resulting electrospun nanofibers are summarized in Table 1. Figure 2 shows the representative SEM images of PET and PET/CD nanofibers. PET $(20 \%$, w/v) solution without CD yielded beaded nanofibers (Fig. 2a). The beaded structures were eliminated, and bead-free 

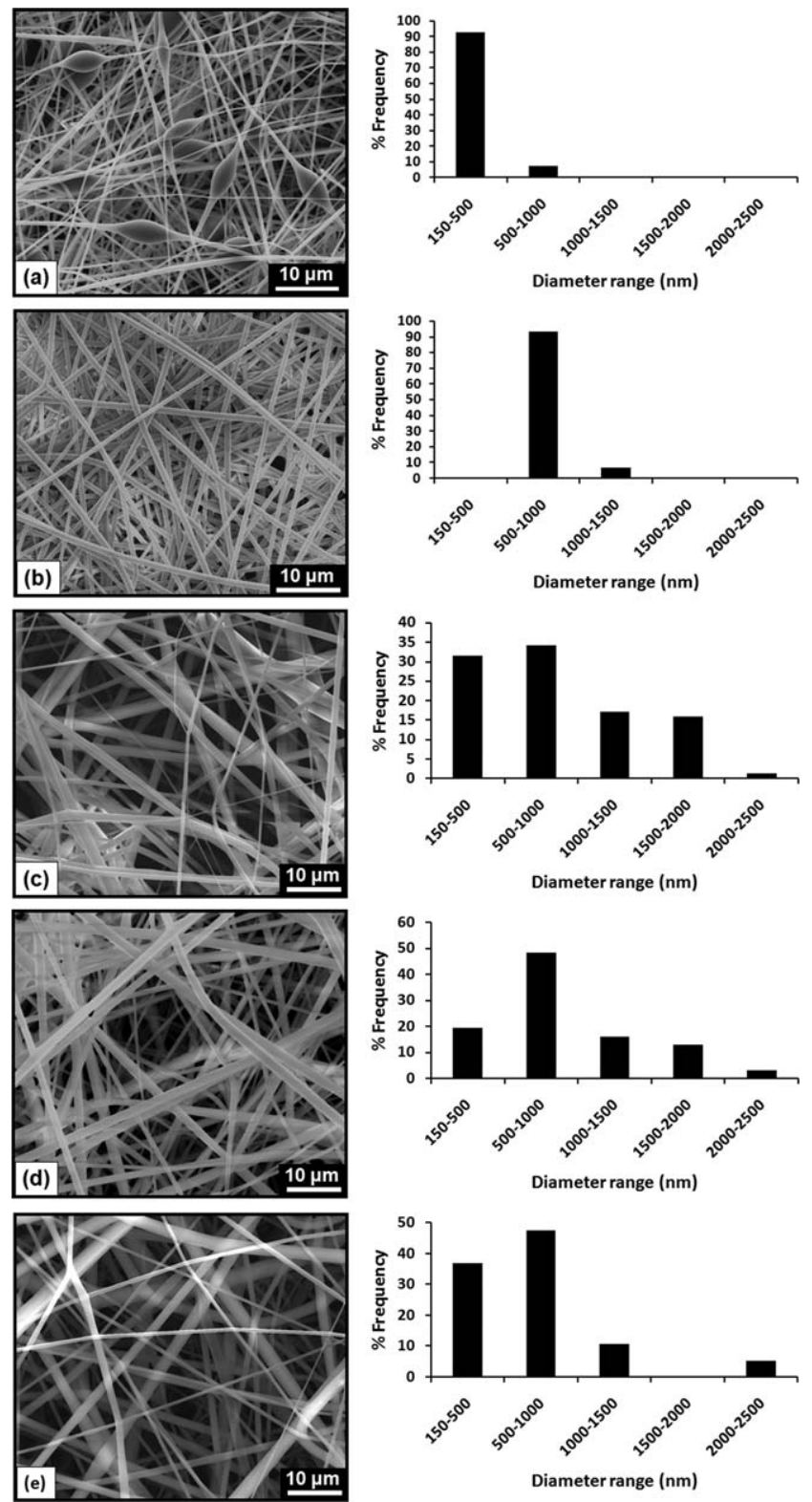

FIG. 2. Representative SEM images and fiber diameter distributions of electrospun nanowebs from the solutions of (a and b) PET at concentrations of $20 \%$ and $22.5 \%$ (w/v), (c) PET/ $\alpha-C D$, (d) PET $/ \beta-C D$, and (e) PET/ $\gamma-C D$.

nanofibers were produced by increasing the PET concentration to $22.5 \%$ (w/v) (Fig. 2b), since the electrified polymer jet could be stretched fully due to higher solution viscosity $[15,16,36]$. Moreover, thicker fibers were yielded from the $22.5 \%(\mathrm{w} / \mathrm{v})$ PET solution having higher viscosity and lower conductivity compared to $20 \%$ (w/v) PET solution, which is compatible with general observation in the literature $[15,16,36]$. Bead-free PET nanofibers obtained from $22.5 \%$ PET solution were used for the rest of the study. High enough concentration/viscosity was required to produce uniform bead-free PET nanofibers. However, bead-free PET/CD nanofibers were obtained by adding $25 \%(\mathrm{w} / \mathrm{w}) \alpha-\mathrm{CD}, \beta-\mathrm{CD}$, and $\gamma-\mathrm{CD}$ to $20 \%$ (w/v) PET solution, individually (Fig. 2c-e). This is possibly due to the higher solution viscosity and conductivity of PET/CD solutions when compared to $20 \%(\mathrm{w} / \mathrm{v})$ PET solution. A possible reason for the viscosity increase may be some interaction between the $C D$ molecules and polymer chains [37], as also pointed out in FTIR discussion. Having required viscosity of PET/CD solutions may be one of the reasons why bead-free PET/CD nanofibers were obtained from lower polymer concentrations. Since the CD causes an increase in the solution conductivity, the possibility of the presence of salt impurity in the CD was considered, and indeed sodium ion was detected in our previous study [38]. The increase in conductivity of the solution resulted in higher stretching of polymer solution under the high electrical field, which is another reason that bead-free fibers could be obtained from lower polymer concentrations. It was concluded that the addition of $\mathrm{CD}$ into polymer solutions improved the electrospinnability, and bead-free nanofibers could be obtained at lower polymer concentrations when compared to the polymer solution without CD. Similar findings were also observed for the electrospinning of other types of polymer systems incorporating CD in our previous studies [37-40]. As mentioned above, generally thicker fibers are yielded from the polymer solutions having higher viscosity and lower conductivity due to the less stretching of the electrified jet $[15,16,36]$. The addition of CD into the PET solutions increased not only viscosity but also conductivity of the solutions. The AFD of the PET/CD nanofibers were larger compared to pristine PET nanofibers obtained from $20 \%$ (w/v) PET solution. This is possibly because of the higher solution viscosity of PET/CD solutions although the solution conductivities were slight higher than that of PET solution. On the other hand, the AFD of PET $(22.5 \% \mathrm{w} / \mathrm{v})$ and PET/CD nanofibers are more or less close to each other without showing any considerable differences. The slight variations in AFD (800-900 nm) among the PET (22.5 \% $/ \mathrm{v})$ and PET/CD nanofibers are summarized in Table 1.

\section{Structural Characterization of the Nanofibers}

The crystalline structures of the nanofibers were investigated by XRD to investigate whether any crystalline $\mathrm{CD}$ aggregates were present in the fiber matrix or not. The XRD patterns of asreceived $\mathrm{CD}(\alpha-\mathrm{CD}, \beta-\mathrm{CD}$, and $\gamma-\mathrm{CD})$ having distinct diffraction peaks in the range of $2 \theta=5^{\circ}-30^{\circ}$ are depicted in Fig. 3a. The diffraction peaks at $2 \theta \cong 12.0^{\circ}, 14.4^{\circ}, 21.7^{\circ}$ in the XRD pattern of as-received $\alpha-\mathrm{CD}, 2 \theta \cong 10.8^{\circ}, 12.6^{\circ}, 19.7^{\circ}, 21.3^{\circ}$ in the $\mathrm{XRD}$ pattern of as-received $\beta$-CD, and $2 \theta \cong 12.3^{\circ}, 16.5^{\circ}, 21.8^{\circ}$ in the XRD pattern of as-received $\gamma$-CD are associated with their cage type crystal structures in which cavity of each $\mathrm{CD}$ molecule is blocked by the adjacent CD molecules [37, 41]. Another CD crystal structure, "channel-type" in which CD molecules are aligned and stacked on top of each other, is generally observed in inclusion complexation of $\mathrm{CD}$ [37, 41, 42]. The broad halo XRD patterns of pristine PET and PET/CD electrospun nanofibrous webs without any strong diffraction peaks are observed in Fig. 3b. The absence of any crystalline peaks of $\alpha-C D, \beta-C D$, and $\gamma$-CD elucidated that all three types of CD were distributed in the PET fiber matrix without forming any phase separated crystal aggregates. Although inclusion complexation between PET chains and $\gamma$-CD was possible under specific conditions and certain solution preparation procedure as reported in literature $[43,44]$, our results suggested that CD and PET chains did not form inclusion complexes. Possibly, the conditions that we used such as solvent, temperature, and host/guest ratio could affect the inclusion complex formation [32]. As a result, the 

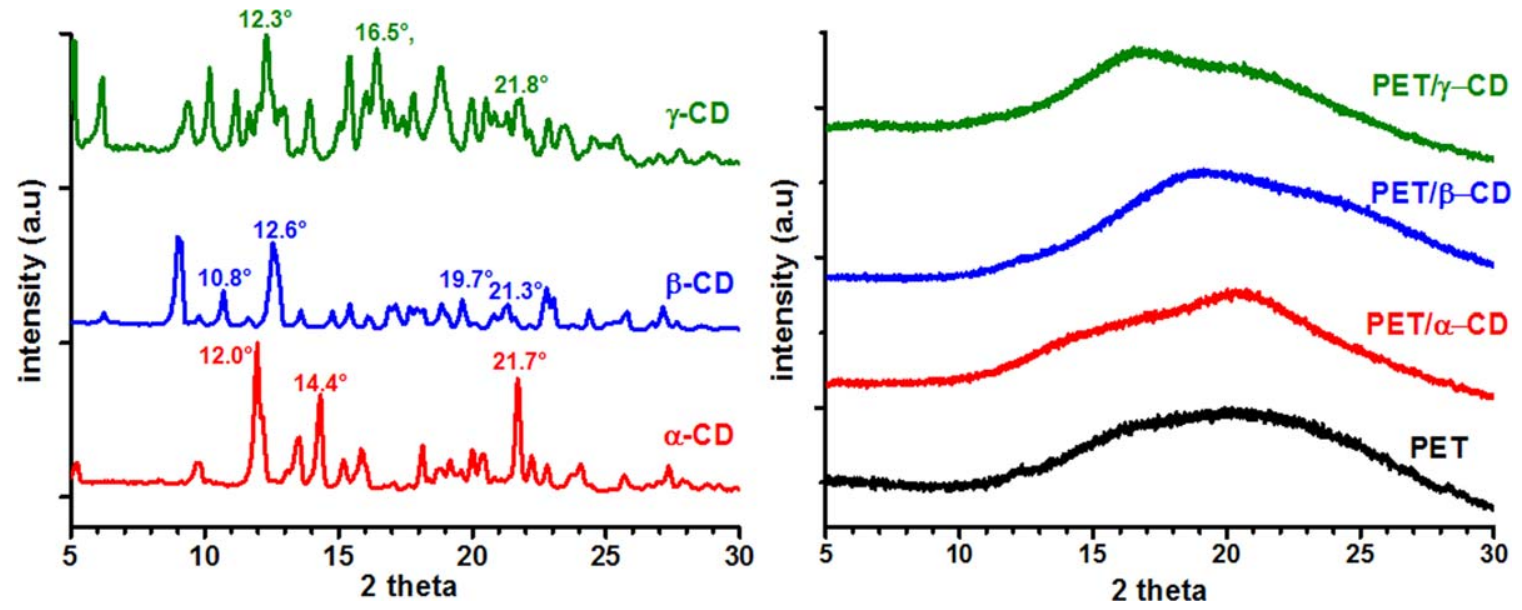

FIG. 3. XRD patterns of as-received CD and the electrospun nanofibers. [Color figure can be viewed in the online issue, which is available at wileyonlinelibrary.com.]

cavity of $\mathrm{CD}$ molecules present onto fiber surface would be available for inclusion complexation with organic waste molecules.

The FTIR spectra of the electrospun PET nanofibers and $\mathrm{PET} / \mathrm{CD}$ nanofibers are shown in Fig. 4. The characteristic peaks in the FTIR spectrum of the pristine PET nanofibers appeared at $1721(\mathrm{C}=\mathrm{O}$ stretching $), 1413(\mathrm{C}-\mathrm{C}$ stretching and $\mathrm{C}-\mathrm{H}$ in plane deformation in aromatic ring), $1339\left(\mathrm{CH}_{2}\right.$ wagging $)$ and $1246(\mathrm{O}=\mathrm{C}-\mathrm{C}$ stretching of ester $), 1102\left(\mathrm{O}-\mathrm{CH}_{2}\right.$ stretching) and 1027 (ring $\mathrm{C}-\mathrm{H}$ in-plane bending), 871 (parasubstituted benzen ring) and $729 \mathrm{~cm}^{-1}(\mathrm{C}-\mathrm{C}$ bending and $\mathrm{C}-\mathrm{H}$ out of plane in aromatic ring) [45]. The characteristic peak of coupled $\mathrm{C}-\mathrm{C} / \mathrm{C}-\mathrm{O}$ stretching vibrations and the antisymmetric stretching vibration of the $\mathrm{C}-\mathrm{O}-\mathrm{C}$ glycosidic bridge of $\mathrm{CD}$ could not be identified in the FTIR spectra of PET/CD nanofibers because of the overlapping of absorption peaks of $\mathrm{CD}$ and PET. Yet, in the enlarged region of FTIR spectra (Fig 4, right side), it was observed that the $\mathrm{O}-\mathrm{CH}_{2}$ stretching and ring $\mathrm{C}-\mathrm{H}$ in-plane bending peaks were shifted to lower wavenumber for $\mathrm{PET} / \mathrm{CD}$ nanofibers when compared to pristine PET nanofibers. The $\mathrm{O}-\mathrm{CH}_{2}$ stretching peak was observed at $1100 \mathrm{~cm}^{-1}$ for
PET/CD nanofibers. More distinctive shift to lower wavenumber was observed for ring $\mathrm{C}-\mathrm{H}$ in-plane bending peak. That is, absorption peak of ring $\mathrm{C}-\mathrm{H}$ in-plane bending was observed at $1022(\mathrm{PET} / \alpha-\mathrm{CD})$ or $1020 \mathrm{~cm}^{-1}(\mathrm{PET} / \beta-\mathrm{CD}$ and $\mathrm{PET} / \gamma-\mathrm{CD})$. The peak shift of these two peaks to lower wavenumbers for PET/CD nanofibers suggested the presence of interaction between PET and CD. FTIR peak shifts were also observed in our previous study for zein/CD nanofibers due to interaction between zein and CD [40].

\section{Thermal Characterization of the Nanofibers}

TGA was used to investigate the thermal characteristics of the nanofibers. The weight percentage of $\mathrm{CD}$ in the resulting electrospun PET/CD nanofibers were determined by TGA. Figure 5 indicates the TGA thermograms of pristine PET and PET/ $\mathrm{CD}$ nanofibers. The initial weight losses below $100^{\circ} \mathrm{C}$ in the TGA thermograms of PET and PET/CD nanofibers were almost same $(\sim 5 \%)$ that were possibly correspond to absorbed water or the residual solvent in the nanofibers. The main degradation of PET nanofibers occurred between $370^{\circ} \mathrm{C}$ and $480^{\circ} \mathrm{C}$ as it was
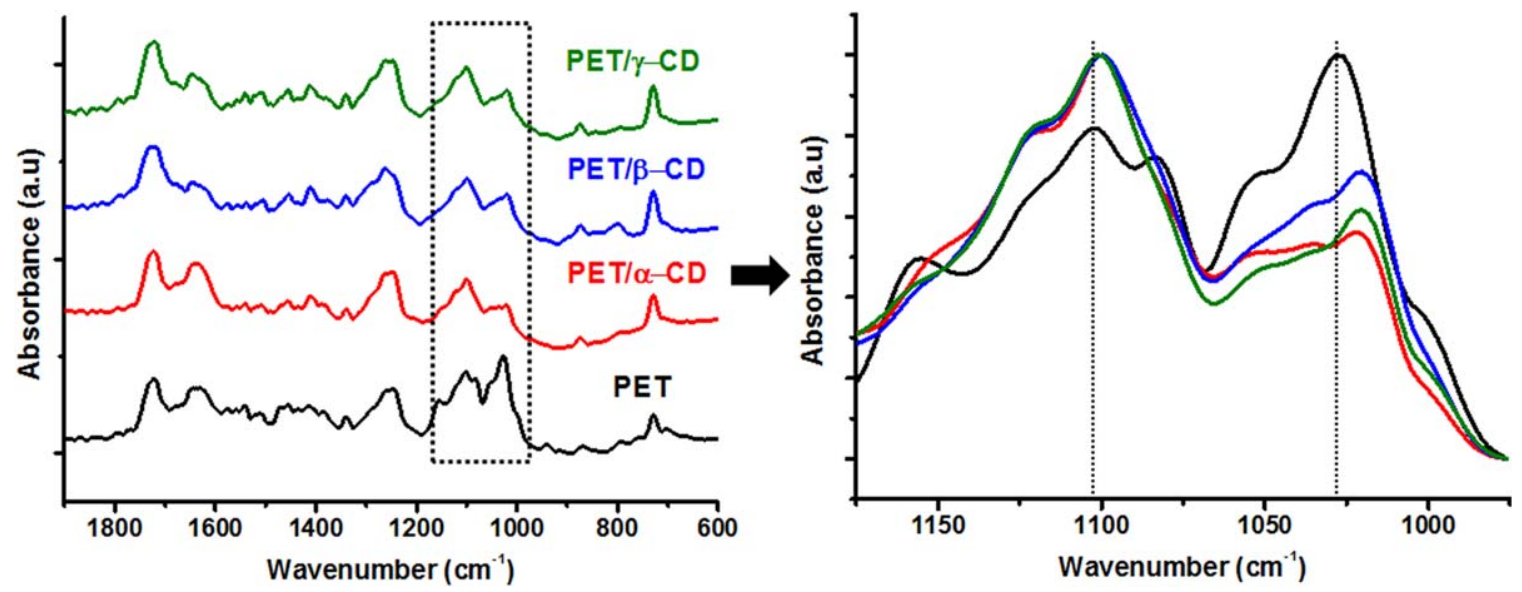

FIG. 4. FTIR spectra of the electrospun nanofibers, and overlay of these spectra in the enlarged region (right side). [Color figure can be viewed in the online issue, which is available at wileyonlinelibrary.com.] 


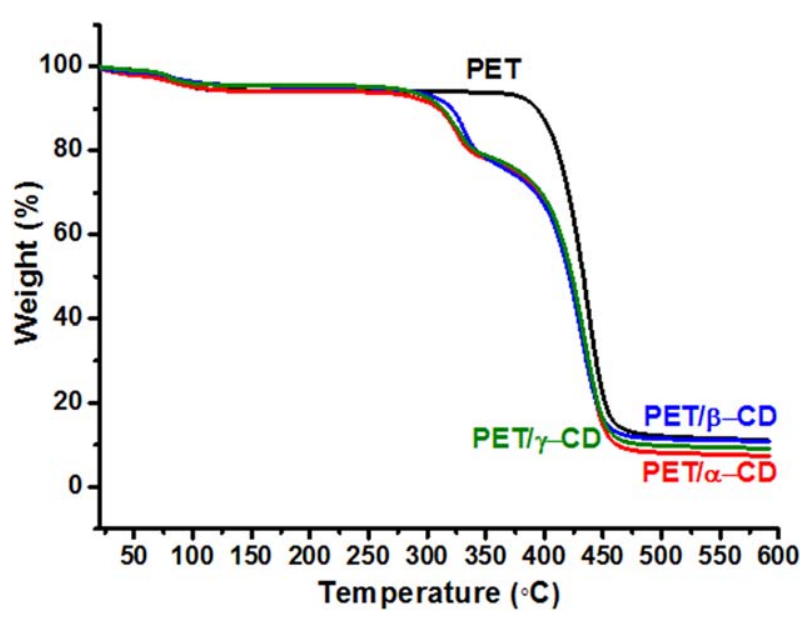

FIG. 5. TGA thermograms of the electrospun nanofibers. [Color figure can be viewed in the online issue, which is available at wileyonlinelibrary.com.]

seen in the TGA thermogram of pristine PET nanofibers. The degradation of $\mathrm{CD}$ was observed in the range of $280-370^{\circ} \mathrm{C}$ $[39,40]$ for PET/CD nanofibers. The observation of CD degradations in the TGA thermograms of PET/CD nanofibers confirmed the incorporation of $\mathrm{CD}$ molecules in the PET fiber matrix. The amount of $\mathrm{CD}$ present in the PET/CD nanofibers was calculated as about $18 \%$ weight in the all PET/CD nanofibers, and this calculation accurately matched with the initial amount of CD added in PET/CD solution. Although 20\% (w/w, with respect to sample) $\mathrm{CD}$ hydrates were used for the preparation of PET/CD solution, actual initial content of CD in PET/ CD solutions were calculated as approximately $18 \%$ (w/w, with respect to polymer), since as-received $\mathrm{CD}$ contains about $10 \%$ water $[39,40]$. Hence, TGA data indicated that the initial CD content in the PET/CD solutions was preserved, and CD molecules were incorporated into the PET nanofibers without any loss during electrospinning process. On the other hand, as it mentioned previously, we did not observe higher weight loss up to $100^{\circ} \mathrm{C}$ for $\mathrm{PET} / \mathrm{CD}$ nanofiber compared to pure PET nanofibers despite of $10 \%$ water in as-received. The reason of this result indicated that the cavities of the $\mathrm{CD}$ molecules are free of water, similar to our previous study [39].

\section{Surface Chemical Characterization of the Nanofibers}

The existence of $\mathrm{CD}$ on the fiber surface is quite important to improve the entrapment efficiency of VOCs by nanofibrous webs [24]. The surface chemical characterization of PET/CD nanofibers was performed by using XPS. Table 2 shows elementary compositions based on wide energy survey spectra of CD and the electrospun nanofibers. The molecular structures of PET and $\mathrm{CD}$ are composed of $\mathrm{C}$ and $\mathrm{O}$ elements, so the XPS survey spectra of $\mathrm{CD}$ and nanofibers indicated two peaks: $\mathrm{C} 1 \mathrm{~s}$ and $\mathrm{O}$ 1s. The percentages of $\mathrm{C} 1 \mathrm{~s}$ and $\mathrm{O} 1 \mathrm{~s}$ onto pristine PET nanofibers were determined as 75.15 and 24.85 , respectively, which was coherent with the literature [46]. We observed that the percentage of $\mathrm{O} 1 \mathrm{~s}$ onto PET/CD nanofibers was increased compared to pristine PET nanofibers. The increasing oxygen ratio on the surface of the PET/CD nanofibers indicated the presence of $\mathrm{CD}$ onto PET/CD nanofibers. From the atomic concentrations in probed volume (Table 2), it is calculated that approximately
$52 \%, 49 \%$, and $43 \%$ of oxygen on the surface of PET/CD nanofibers originated from $\alpha-\mathrm{CD}, \beta-\mathrm{CD}$, and $\gamma-\mathrm{CD}$, respectively. This indicates that the most of $\mathrm{CD}$ molecules located on the fiber surface possibly due to phase separation from the PET matrix during the electrospinning. In fact, higher amount of surface-associated $\mathrm{CD}$ is desired since $\mathrm{CD}$ molecules that are present on the fiber surface have capability of complex formation with VOCs.

To verify the existence of CD onto surface of PET/CD nanofibers, high energy resolution $\mathrm{O}$ 1s spectra of pristine PET and $\mathrm{PET} / \mathrm{CD}$ nanofibers were also recorded. Since the O 1s XPS spectra of $\mathrm{PET} / \alpha-\mathrm{CD}, \mathrm{PET} / \beta-\mathrm{CD}$, and $\mathrm{PET} / \gamma-\mathrm{CD}$ nanofibers were almost same, only one of them $(\mathrm{PET} / \gamma-\mathrm{CD})$ was given in Fig. 6 to compare with the O 1s spectrum of pristine PET nanofibers. Distinctive two fitting peaks (O 1s \#1 and $\mathrm{O} 1 \mathrm{~s} \# 2)$ are represented within the $\mathrm{O} 1 \mathrm{~s}$ spectra of pristine PET nanofibers (Fig. 6) at peak binding energies of 531.8 and $533.39 \mathrm{eV}$ due to $\pi$-bonded oxygen $(\mathrm{C}=\mathrm{O} *)$ and $\sigma$-bonded oxygen $(\mathrm{C}-\mathrm{O} * \mathrm{C})$ in PET structure, respectively [47-49]. Theoretical ratio of these two components is 50:50 in PET structure, and therefore the ratio of these peaks $(50.76: 48.22)$ was determined coherently. There is also one additional peak ( $\mathrm{O} 1 \mathrm{~s} \# 3)$ having very low ratio ( $\sim 1.02 \%$ of the total $\mathrm{O} 1 \mathrm{~s}$ ratio) at peak binding energy of $535.2 \mathrm{eV}$ because of absorbed water [47]. Besides of the peaks assigned to PET components $(\mathrm{C}-\mathrm{O} * \mathrm{C}, \mathrm{C}=\mathrm{O} *)$ and adsorbed $\mathrm{H}_{2} \mathrm{O}$, the additional fitting peak $(\mathrm{O} 1 \mathrm{~s} \# 4)$ was also observed in the $\mathrm{O} 1 \mathrm{~s}$ spectrum of PET/CD nanofibers (Fig. 6b) at peak binding energy of $533.15 \mathrm{eV}$ owing to hydroxyl groups of $\mathrm{CD}$ $(\mathrm{C}-\mathrm{O} * \mathrm{H})$. This finding confirmed the presence of the $\mathrm{CD}$ on the surface of the PET/CD.

The surface properties of electrospun nanofibers were also characterized by water contact angle measurement. Water contact angle on the pure PET nanofibers was determined as $145.7 \pm 3.9^{\circ}$ indicating generally known hydrophobic feature of PET fibers [50, 51]. On the other hand, the contact angles of the PET/CD webs could not be measured, since droplets were absorbed on the surface of the fibers where oxygen-containing polar groups resulted in the significant enhancement of hydrophilicity [52]. This increased hydrophilicity of the webs is another evidence of the existence of $\mathrm{CD}$ on the fiber surface. The video taken during the water contact angle measurements further support the hydrophobicity of PET nanofibers and hydrophilicity of PET/CD nanofibers.

As discussed previously, hydrophilic nature CD molecules could phase separate from the hydrophobic PET matrix during the solvent evaporation in the electrospinning process and heterogeneously mixed throughout the fiber matrix [23]. Moreover,

TABLE 2. Atomic concentrations generated from XPS wide energy survey scans.

\begin{tabular}{lll}
\hline Samples & $\mathrm{C}(\%)$ & $\mathrm{O}(\%)$ \\
\hline$\alpha-\mathrm{CD}$ & 58.45 & 41.55 \\
$\beta$-CD & 57.69 & 42.31 \\
$\gamma$-CD & 58.47 & 41.53 \\
$\mathrm{PET}$ & 75.14 & 24.86 \\
$\mathrm{PET} / \alpha-\mathrm{CD}$ & 66.39 & 33.61 \\
$\mathrm{PET} / \beta-\mathrm{CD}$ & 66.57 & 33.43 \\
$\mathrm{PET} / \gamma-\mathrm{CD}$ & 67.89 & 32.11 \\
\hline
\end{tabular}



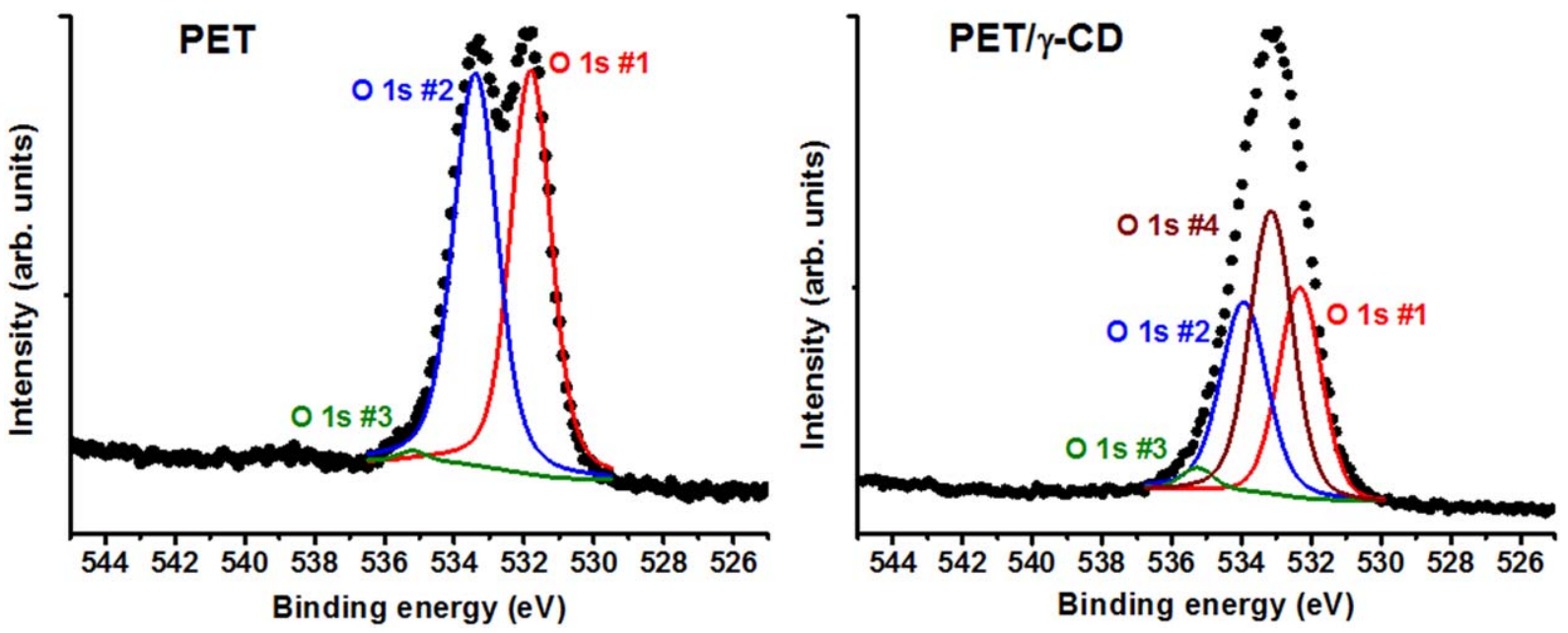

FIG. 6. O 1s high resolution XPS scans of electrospun nanofibers of PET and PET/ $\gamma$-CD. [Color figure can be viewed in the online issue, which is available at wileyonlinelibrary.com.]

in such blend systems, it is proposed that the lower molecular weight component generally migrate to the surface due to energetic and entropy effects [53-56]. It is likely because of those the surface analysis results by XPS and contact angle measurement clearly indicated that there is a surface enrichment or segregation of $\mathrm{CD}$ molecules on the fibers.

\section{Mechanical Characterization of the Nanofibers}

We used DMA to investigate the effect of $\mathrm{CD}$ on the mechanical properties of the nanofibers. The mechanical properties of electrospun nanofibers determined from the stress-strain curves for the nanofibers were summarized in Table 3 . We observed that ultimate stress was nearly two times higher for PET/CD nanofibers than pristine PET nanofibers, while elongation at break of PET and PET/CD nanofibers was found almost same. Specifically, the young modulus of the PET/CD nanofibers was three times as strong compared to PET nanofibers. These results were possibly due to interaction between PET and $\mathrm{CD}$ that was mentioned in the FTIR discussion. Likely, the interaction gave the stiffening effect to the fibers.

\section{Entrapment of Aniline Vapor by Nanofibrous Webs}

The entrapment performance of the PET and PET/CD nanofibrous webs was investigated by using aniline vapor as a model VOC. Aniline is commonly used in industry for certain purposes and it is one of the common VOCs present in the environment. $\mathrm{CD}$ can form inclusion complex with aniline [24, 57], and

TABLE 3. Summary of the mechanical properties of electrospun nanofibers.

\begin{tabular}{lccc}
\hline Samples & $\begin{array}{c}\text { Ultimate } \\
\text { stress }(\mathrm{MPa})\end{array}$ & $\begin{array}{c}\text { Elongation } \\
\text { at break }(\%)\end{array}$ & $\begin{array}{c}\text { Young } \\
\text { modulus }(\mathrm{MPa})\end{array}$ \\
\hline $\mathrm{PET}$ & $9 \pm 4$ & $73 \pm 11$ & $59 \pm 12$ \\
$\mathrm{PET} / \alpha-\mathrm{CD}$ & $18 \pm 4$ & $74 \pm 10$ & $183 \pm 32$ \\
$\mathrm{PET} / \beta$-CD & $12 \pm 7$ & $62 \pm 26$ & $126 \pm 64$ \\
$\mathrm{PET} / \gamma-\mathrm{CD}$ & $14 \pm 5$ & $78 \pm 18$ & $142 \pm 43$ \\
\hline
\end{tabular}

therefore we have chosen aniline as a model VOC as proof of concept study. The amount of aniline entrapped by PET, PET $/ \alpha$ $\mathrm{CD}, \mathrm{PET} / \beta-\mathrm{CD}$, and $\mathrm{PET} / \gamma-\mathrm{CD}$ nanofibrous webs were calculated by HPLC and the data are given in Fig. 7. The absorption of approximately $1300 \mathrm{ppm}$ aniline by pristine PET nanofibers was observed. On the other hand, the amount of entrapped aniline was considerable higher for PET/CD nanofibrous webs when compared to pristine PET web. This is simply because the surface-associated CD molecules increased the entrapment efficiency of PET nanofibers by facilitating complex formation with aniline. Moreover, it is also possible that the higher amount of aniline can be absorbed by PET/CD nanofibers compared to PET nanofibers due to the more hydrophilic nature of PET/CD nanofibers. So, our findings suggested that better entrapment efficiency of aniline by PET/CD was both due to the absorption of aniline by high surface area of nanofibers and also by inclusion complexation of aniline with $\mathrm{CD}$. The complex formation of aniline with CD cavity is illustrated in Fig. 1c, schematically. Here, we observed that PET/ $\alpha-\mathrm{CD}$ and $\mathrm{PET} / \beta-\mathrm{CD}$ nanofibrous webs captured approximately $2600 \mathrm{ppm}$ of aniline, while the amount of aniline entrapped by $\mathrm{PET} / \gamma-\mathrm{CD}$ nanofibrous web was

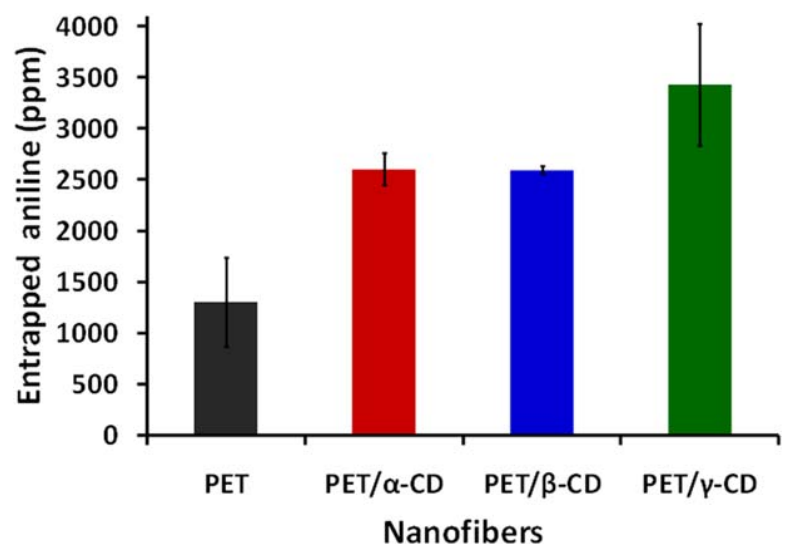

FIG. 7. The amount of entrapped aniline ( $\mathrm{ppm}$ ) by the electrospun nanofibers. [Color figure can be viewed in the online issue, which is available at wileyonlinelibrary.com.] 
approximately $3400 \mathrm{ppm}$ at the end of entrapment test. PET/ $\gamma$ CD presented the highest entrapment efficiency among the other samples, although the surface of this sample has less amount of CD. This is possibly due to bigger size of $\gamma$-CD cavity which could complex with more amount of aniline [57]. In brief, our results showed that all three PET/CD nanofibers can effectively entrap aniline vapor from the surrounding due to their very large surface area along with inclusion complexation capability of surface-associated $\mathrm{CD}$ on the nanofibers.

\section{CONCLUSION}

Here, we produced CD functionalized electrospun PET nanofibers by using three different types of native $\mathrm{CD}(\alpha-\mathrm{CD}, \beta-\mathrm{CD}$, and $\gamma$-CD) having $25 \%(\mathrm{w} / \mathrm{w})$ loading. XRD studies of PET/CD nanofibers suggested that $\mathrm{CD}$ molecules were distributed in the nanofiber matrix without any crystalline $C D$ aggregation. The interaction between $\mathrm{CD}$ and PET could carry out, since FTIR peak shift was observed. TGA data indicated that the initial weight percentage of $\mathrm{CD}$ in polymer solution was preserved in the fiber matrix after the electrospinning of PET/CD nanofibers. XPS studies and contact angle measurements of PET/CD nanofibers confirmed that most of $\mathrm{CD}$ molecules were located on the surface of PET nanofibers. Higher mechanical properties were observed for PET/CD nanofibers compared to pristine PET nanofibers. The entrapment performance of the resulting PET/CD nanofibers was tested by removal of aniline in vapor phase. Higher amount of aniline was entrapped by PET/CD nanofibrous webs when compared to pristine PET web since the surface associated $\mathrm{CD}$ molecules increased the entrapment efficiency of the nanofibers by inclusion complex formation with aniline. The amount of aniline entrapped by PET $/ \gamma$-CD web was higher than that of $\mathrm{PET} / \alpha-\mathrm{CD}$ and $\mathrm{PET} / \beta-\mathrm{CD}$ webs possibly due to bigger cavity size of $\gamma$-CD. Our results suggest that CD functionalized electrospun PET nanofibers can be promising filtering materials for air filtration and the removal of VOCs due to very high surface area of nanofibrous web and surface associated CD molecules having inclusion complexation capability with VOCs.

\section{REFERENCES}

1. R. Balamurugan, S. Sundarrajan, and S. Ramakrishna, Membranes, 1, 232 (2011).

2. V. Thavasi, G. Singh, and S. Ramakrishna, Energy Environ. Sci., 1, 205 (2008).

3. R. Barhate and S. Ramakrishna, J. Membr. Sci., 296, 1 (2007).

4. A. Patanaik, V. Jacobs, and R.D. Anandjiwala, J. Membr. Sci., 352, 136 (2010).

5. R. Ramaseshan, S. Sundarrajan, Y. Liu, R. Barhate, N. Lala, and S. Ramakrishna, Nanotechnology, 17, 2947 (2006).

6. S. Sundarrajan and S. Ramakrishna, J. Mater. Sci., 42, 8400 (2007).

7. R. Ramaseshan and S. Ramakrishna, J. Am. Ceram. Soc., 90, 1836 (2007).

8. E. Scholten, L. Bromberg, G.C. Rutledge, and T.A. Hatton, ACS Appl. Mater. Interfaces, 3, 3902 (2011).

9. Z. Huang, Y. Zhang, M. Kotaki, and S. Ramakrishna, Compos. Sci. Technol., 63, 2223 (2003).

10. R.S. Barhate, C.K. Loong, and S. Ramakrishna, J. Membr. Sci., 283, 209 (2006).
11. R. Gopal, S. Kaur, Z. Ma, C. Chan, S. Ramakrishna, and T. Matsuura, J. Membr. Sci., 281, 581 (2006).

12. A. Podgorski, A. Bałazy, and L. Gradon, Chem. Eng. Sci., 61, 6804 (2006).

13. Y.C. Ahn, S.K. Park, G.T. Kim, Y.J. Hwang, C.G. Lee, H.S. Shin, and J.K. Lee, Curr. Appl. Phys., 6, 1030 (2006).

14. L. Persano, A. Camposeo, C. Tekmen, and D. Pisignano, Macromol. Mater. Eng., 298, 504 (2013).

15. S. Ramakrishna, An Introduction to Electrospinning and Nanofibers, World Scientific Publishing Company Incorporated, Singapore (2005).

16. J.H. Wendorff, S. Agarwal, A. Greiner, Electrospinning: Materials, Processing, and Applications, Wiley, New York (2012).

17. P. Heikkilä, A. Taipale, M. Lehtimäki, and A. Harlin, Polym. Eng. Sci., 48, 1168 (2008).

18. H. Matsumoto and A. Tanioka, Membranes, 1, 249 (2011).

19. A. Dasari, J. Quirós, B. Herrero, K. Boltes, E. García-Calvo, and R. Rosal, J. Membr. Sci., 405, 134 (2012).

20. M. Roso, S. Sundarrajan, D. Pliszka, S. Ramakrishna, and M. Modesti, Nanotechnology, 19, 285707 (2008).

21. J.D. Schiffman, L.A. Stulga, and C.L. Schauer, Polym. Eng. Sci., 49, 1918 (2009).

22. T. Uyar, R. Havelund, Y. Nur, J. Hacaloglu, F. Besenbacher, and P. Kingshott, J. Membr. Sci., 332, 129 (2009).

23. T. Uyar, R. Havelund, J. Hacaloglu, F. Besenbacher, and P. Kingshott, ACS Nano, 4, 5121 (2010).

24. T. Uyar, R. Havelund, Y. Nur, A. Balan, J. Hacaloglu, L. Toppare, F. Besenbacher, and P. Kingshott, J. Membr. Sci., 365, 409 (2010).

25. S. Kaur, M. Kotaki, Z. Ma, R. Gopal, and S. Ramakrishna, Int. J. Nanosci., 5, 1 (2006).

26. W. Zhang, M. Chen, and G. Diao, Carbohydr. Polym., 86, 1410 (2011).

27. A.H. Jadhav and H. Kim, Adv. Mater. Res., 622, 827 (2013).

28. F. Kayaci, Z. Aytac, and T. Uyar, J. Hazard. Mater., 261, 286 (2013).

29. W. Zhang, M. Chen, B. Zha, and G. Diao, Phys. Chem. Chem. Phys., 14, 9729 (2012).

30. J. Szejtli, Chem. Rev., 98, 1743 (1998).

31. A. Hedges, Chem. Rev., 98, 2035 (1998).

32. E. Del Valle, Process Biochem., 39, 1033 (2004).

33. T. Badr, K. Hanna, and C. De Brauer, J. Hazard. Mater., 112, 215 (2004).

34. A. Yudiarto, S. Kashiwabara, Y. Tashiro, and T. Kokugan, Sep. Purif. Technol., 24, 243 (2001).

35. M.V. Rekharsky and Y. Inoue, Chem. Rev., 98, 1875 (1998).

36. T. Uyar and F. Besenbacher, Polymer, 49, 5336 (2008).

37. T. Uyar, A. Balan, L. Toppare, and F. Besenbacher, Polymer, 50, 475 (2009).

38. T. Uyar, R. Havelund, J. Hacaloglu, X. Zhou, F. Besenbacher, and P. Kingshott, Nanotechnology, 20, 125605 (2009).

39. T. Uyar and F. Besenbacher, Eur. Polym. J., 45, 1032 (2009).

40. F. Kayaci and T. Uyar, Carbohydr. Polym., 90, 558 (2012).

41. C.C. Rusa, T.A. Bullions, J. Fox, F.E. Porbeni, X. Wang, and A.E. Tonelli, Langmuir, 18, 10016 (2002). 
42. W. Saenger, J. Jacob, K. Gessler, T. Steiner, D. Hoffmann, H. Sanbe, K. Koizumi, S.M. Smith, and T. Takaha, Chem. Rev., 98, 1787 (1998).

43. M. Wei, T. A. Bullions, C. C. Rusa, X. Wang, A. E. Tonelli, $J$. Polym. Sci. Part B: Polym. Phys., 42, 386 (2004).

44. T. Bullions, E. Edeki, F. Porbeni, M. Wei, X. Shuai, C. Rusa, and A. Tonelli, J. Polym. Sci. Part B: Polym. Phys., 41, 139 (2003).

45. M. Djebara, J.P. Stoquert, M. Abdesselam, D. Muller, and A.C. Chami, Nucl. Instr. Meth. Phys. Res. B, 274, 70 (2012).

46. N. Hayes, G. Beamson, D. Clark, D.L. Law, and R. Raval, Surf. Interface Anal., 24, 723 (1998).

47. S. Ben Amor, M. Jacquet, P. Fioux, and M. Nardin, Mater. Chem. Phys., 119, 158 (2010).

48. S.B. Amor, M. Jacquet, P. Fioux, and M. Nardin, Appl. Surf. Sci., 255, 5052 (2009).

49. A. Ektessabi and K. Yamaguchi, Thin Solid Films, 377, 793 (2000).
50. Y. Cho, D. Cho, J.H. Park, M.W. Frey, C.K. Ober, and Y.L. Joo, Biomacromolecules, 13, 1606 (2012).

51. A.E. Özçam, K.E. Roskov, J. Genzer, and R.J. Spontak, ACS Appl. Mater. Interfaces, 4, 59 (2012).

52. T. Jacobs, R. Morent, N. De Geyter, P. Dubruel, and C. Leys, Plasma Chem. Plasma Process., 32, 1039 (2012).

53. A. Hariharan, S. K. Kumar, and T. P. Russell, Macromolecules, 23, 3584 (1990).

54. M.T. Hunley, A. Harber, J.A. Orlicki, A.M. Rawlett, and T.E. Long, Langmuir, 24, 654 (2008).

55. D. Walton and A. Mayes, Phys. Rev. E, 54, 2811 (1996).

56. D. Walton, P. Soo, A. Mayes, S. Sofia Allgor, J. Fujii, L. Griffith, J. Ankner, H. Kaiser, J. Johansson, and G. Smith, Macromolecules, 30, 6947 (1997).

57. T. Uyar, M.A. Hunt, H.S. Gracz, and A.E. Tonelli, Cryst. Growth Des., 6, 1113 (2006). 